\title{
Lexical Cohesion: An Issue only in the Foreign Language?
}

\author{
Hüseyin Kafes \\ Anadolu University, School of Foreign Languages, 26000 Eskisehir, Turkey \\ Tel: 90-505-240-9933 E-mail: hkafes@gmail.com; hkafes@anadolu.edu.tr
}

Received: November 13, 2011

Accepted: December 13, 2011

Published: March 1, 2012

doi:10.5539/elt.v5n3p83

URL: http://dx.doi.org/10.5539/elt.v5n3p83

\begin{abstract}
The purpose of this study was to investigate Turkish EFL learners' ability in composing cohesive texts in their first language and in English as their foreign language, and to examine whether there are similarities between lexical reiteration cohesive devices they employ in composing cohesive texts both in Turkish and in English. The study was conducted with the participation of 40 students. The data of the study came from written accounts of a story in both languages based on a set of pictures with eight episodes. The analysis of the data has revealed striking similarities between English and Turkish in terms of the employment of lexical reiteration cohesive devices. The results have shown that repetition of the same lexical items was by far the most frequently used type of lexical cohesion in both languages. The findings are discussed in terms of their implications for writing.
\end{abstract}

Keywords: Writing in Turkish/English, Cohesion, Lexical reiteration cohesive devices

\section{Introduction}

\subsection{Introduction to the Study}

With the emergence and popularity of communicative competence, discourse competence, which is one of its prominent features, has gained popularity in language pedagogy. In line with the significance this notion supplies to the ability to produce unified written and/or spoken discourse that shows coherence and cohesion (Richards, Plat, and Plat 1992), learners' ability to produce successive sentences that are linked through rules of discourse has been highlighted. In the meantime, in the light of insights gained from a large quantity of discourse-based studies on the process of coherence and cohesion behavior of EFL/ESL learners, methodologists and language teachers have realized the need for language learners to acquire more than grammar knowledge to produce meaningful and coherent texts in English.

In conformity with the saliency attached to coherence and cohesion in discourse, the focus of research since the early 1980s on writing has been coherence problems of EFL/ESL learners. Despite its importance in discourse, coherence has been approached from different perspectives and thus defined vaguely. While some view coherence as a feature internal to text, some others claim that it cannot be considered separately from the reader. Those who maintain that coherence is integral to text support the Hallidayan view, according to which, coherence consists of cohesion, the linking of sentences, and unity, sticking to the point. Similarly, cohesion, one of the fundamental features of texture according to Halliday and Hasan (1976:2), “...result from the combination of semantic configurations of two kinds: those of register, and those of cohesion, which enables a text to function as a text." While Goutsas (1997) emphasizes the importance of text cohesion to show text relations, Givon (1983) considers that cohesive devices, through which cohesion is realized, enable communicators to produce language which is connected, coherent, and relevant to the subject at hand.

Though cohesion is one of the fundamental qualities of effective writing, according to Lee (2002:135), cohesion together with coherence, "is often considered as a fuzzy concept", leaving teachers being aware of the benefits of teaching coherence and cohesion to students without knowing how to teach them. Despite the vagueness faced in the definition of this important concept, Johns (1986) says that review of literature on coherence provides a number of principles which can help instructors in the teaching of it. According to Johns (1986:251), these principles are:

- Coherence is text based and consists of the ordering and interlinking of propositions within a text by use of appropriate information structure (including cohesion).

- $\quad$ At the same time, coherence is reader based; the audience and assignment must be consistently considered as the discourse is produced and revised. 
- Instructors have an obligation to teach coherence comprehensively, that is, to take into account these two approaches (text based and reader based), at a minimum.

With the emergence of Contrastive Hypothesis in general and Contrastive Rhetoric in particular, attempts were and are still being made to help language learners to investigate the similarities and/or differences between writing in the first language and the second/foreign language. Many of the studies done in this field focusing on the use of the first language in the second language composing process (Wang and Wen; 2002, Kobayashi and Rinnert; 2002) confirm the claim that "the L2 writing process is a bilingual event." As for the relationship between writing in L1 and L2, a number of studies have been carried out (Leki, 2002: 64). Most of these studies, which generally focused on the mental processes employed in L2 writing, come up with some important findings, namely:

- $\quad$ Proficient L2 writers focus on content, and not only on form, as they write,

- $\quad$ L2 writers need to reach a threshold level of proficiency in L2 before they can engage the efficient writing processes they use in L1,

- Writers' processes vary widely across individuals though they may remain more or less consistent from L1 to L2 (Arndt, 1987),

- $\quad$ Shifting to L1 can be a very useful strategy for generating ideas and stimulating more complex thinking in L2.

Regardless of these and other similar claims emphasizing the benefit of using L1 in L2 writing, the use of L1 in L2 writing is approached cautiously and skeptically. As put forth by Friedlander (1990), ESL/EFL student writers are generally advised to refrain from using their native languages as much as possible in the process of composing in the target language. This line of thought is tied to the belief that relying on the native language affects the composition process in L2 negatively. Contrary to this widely held view, a number of studies claim that the effects of the first language on composing in the second language do not necessarily have to be negative. A number of studies cited in Friedlander (1990) assert that both macro-structure and micro-structure skills are transferred from L1 to L2 underlying the claim that writing knowledge is transferable to the target language. While Jones and Tetroe's (1987) study indicates that both good and weak writing skills and strategies can be transferred from L1 to L2, Lay (1982), and Jones \& Tetroe (1987) have found evidence of first language assisting writers in the L2 writing process.

Contrary to the expectation that learners with a relatively high level of proficiency in English should be able to produce cohesive/coherent written work, our learners, based on our observation from their writing courses, seem to have difficulty in doing so. This personal observation is supported by Emeksiz's study, which found that Turkish EFL learners with a high level of English proficiency had problems using topical noun phrases coherently (1998). As there does not seem to be a one-to-one relationship between level of proficiency in English and success in producing cohesive/coherent pieces of writing, it is likely that there are some other pertaining causes of the problem. One of the possible reasons why student writers have this difficulty could be due to their inefficiency in producing cohesive texts in their native language. Another cause of the problem could be that they may not create local and global coherence due to their insufficient knowledge of considering a text as a whole, focusing on the semantic relationship between sentence topics and the discourse topic. The final reason could be that they may not know how to foreground and background information and what information to foreground and what to background.

\subsection{Coherence}

Along with the shift of focus of discourse in linguistics towards the end of the 1960s, linguists began to look at language at discourse level rather than sentence level, paying less attention to the components of language such as grammar or the sound system of a language separately. In parallel with this change of focus, coherence was viewed differently by different authors, and thus was attributed different definitions. Grabe and Kaplan (1986) support this claim about the controversial nature of coherence, emphasizing the existence of little consensus on an overall definition of coherence. According to Grabe \& Kaplan 1996, this controversy is due to the shift of emphasis from sentence level to discourse level. As text-linguistics gained popularity, coherence began to be defined in relation to text rather than in terms of between-sentence connections. While some regard coherence as a linguistic, text-based entity, some others regard it as non-linguistic, that is, reader-based. Leaving aside these two sources of the definitions of coherence, based on his review of literature on textual elements, Lee (2002: 139) defines coherence as:

- Connectivity of the surface text evidenced by the presence of cohesive devices (Halliday \& Hasan, 1976).

- $\quad$ An information structure which guides the reader in understanding the text and contributes to the topical development of the text (Connor \&Farmer, 1990; Firbas, 1986; Lautamatti, 1987). 
- $\quad$ Connectivity of the underlying concept evidenced by relations between propositions and how these relations contribute to the overall discourse theme and organization (Kintsnh \& van Dijk, 1978).

- A macro-structure with a characteristic pattern or shape appropriate to its communicative purpose and context of situation (Hoey, 1983, 1991).

- $\quad$ Reader-based writing signaled by appropriate metadiscoursal features (Cheng \& Stefensen, 1996; Crismore et al., 1973).

Defining coherence as something that is "not an inherent property of text patterns but has a multiplicity of sources both within and outside the text", Goutsos (1997) views coherence as an entity referring to the total meaning of text, which confers unity and connectedness. While agreeing on the idea that a text by definition is coherent, Goutsos (1997) views organization, context of situation, and schemata of background knowledge as some of the important sources of coherence. As can be seen, coherence is defined in relation to a number of things, indicating that neither the text alone nor the cohesive ties used in the text can account for a meaningful text, which in turn requires that a number of other factors exist together. De Breaugrande and Dressler (1981) mention seven criteria for textuality: cohesion, coherence, intentionality, acceptability, informativity, situationality, and intertextuality. Regardless of the definition of coherence approached or defined differently by different authors, it has always been dealt with in connection with text, since its continuance is dependent on text. As such, some terms closely related with text such as texture gain importance. Halliday \& Hasan (1976) consider text as a semantic unit, unified regardless of its length and its medium, and claim that texture is something which "distinguishes a text from something that is not a text."

Since coherence is closely related with text and as what makes a text seems to be the sum of features of the text or the relations in it, this relation is of crucial concern. In looking at text relations, Goutsos (1997: 140) identified the following items as the main text relations covered in the literature: Cohesive devices, thematic progression, rhetorical relations, macrostructures, lexical patterns, vocabulary flow, argumentative patterns, schematic structure, and intentional structure.

\subsection{Cohesion}

Cohesion, a semantic concept rather than a structural one, can be defined roughly as the set of possibilities in the language that allow for the text to hang together. It is the semantic relations established via cohesive devices within a text. These semantic relations are what enable a passage of speaking or writing to function as a text. Halliday \& Hasan (1976), who analyzed and described cohesion most comprehensively, interpret cohesion as "the set of semantic resources for linking a sentence with what has gone before." They claim that cohesion makes the interpretation of an item in discourse with reference to some other item in discourse. Since cohesion is a semantic relation rather than a structural one, it is not restricted by sentence boundaries. It can be found both within a sentence between sentences.

Explaining cohesion, Halliday \& Hasan (1976) maintain that it occurs where the interpretation of some element in the discourse is dependent on that of another. The one presupposes the other, in the sense that it cannot be effectively decoded except by resource to it. When this happens, a relation of cohesion is set up, and the two elements, the presupposing and the presupposed, are thereby at least potentially integrated into a text. Halliday \& Hasan (1976) identify and classify cohesion into five categories: reference, substitution, ellipsis, conjunction, and lexical cohesion. The first four of these types are also called grammatical cohesion. As the main concern of the study is only the first three types of lexical cohesion, that is, reiteration, synonymy or near-synonym, or superordinate, they will be dealt with in the next section in detail.

\subsubsection{Lexical Cohesion}

Lexical cohesion, as the name implies, can be defined as cohesion that is created via the use of vocabulary. It is the central device to make a text hang together experientially which defines the aboutness of a text Halliday \& Hasan (1976). In Halliday \& Hasan's framework, lexical reiteration is a mechanism of producing cohesion in text by means of repetition of lexical items that are observable at the surface of the text. In other words, lexical cohesion is the predominant means of connecting sentences in discourse. Halliday \& Hasan (1976) identify two major subclasses of lexical cohesion: reiteration and collocation. Lexical reiteration consists of four categories: repetition of the same word, use of a synonym, use of a superordinate, and use of a general word. Nunan (1999: 123) exemplifies the different types of reiteration as:

\section{Repetition}

What we lack in a newspaper is what we should get. In a word, a "popular" newspaper may be the winning ticket.

\section{Synonym}

You could try reversing the car up the slope. The incline isn't all that steep. 


\section{Superordinate}

Pneumonia has arrived with cold and wet conditions. The illness is striking everyone from infants to the elderly.

\section{General word}

A: Did you try the steamed buns?

B: Yes, I didn't like the things much.

As the second underlined words or phrases in the above texts refer back to a previously mentioned entity, they serve a similar semantic function as cohesive reference.

As it is projected by Halliday \& Hasan (1976: 278), "Reiteration is at one end of the scale; while the use of a general word to refer back to a lexical item, at the other end of the scale; and a number of things in between-the use of synonym, or superordinate". This common use of reiteration has been confirmed by Hasan (1984) and Hoey (1991), who found that around forty to fifty percent of a text's cohesive ties are lexical. Apart from this prominent qualitative dimension of cohesion (including lexical cohesion) in creating cohesive written discourse, Witte \& Faigley (1981) and Guiju's (2005) draw attention to the qualitative dimension of it underlying an undeniable relationship between lexical cohesion and writing quality. In detailing this relationship, Witte \& Faigley (1981:197) states "the relative frequency of lexical cohesion gives another indication that the writers of high-rated essays are better able to expand and connect their ideas than the writers of low-rated essays..."

This crucial role of lexical cohesive devices has found its fair share in the numerous studies done on lexical cohesion in written discourse. Jimenez \& Moreno (2005) underlined four inclinations in research:

a) studies on the frequency of cohesive ties used by language learners (Anderson, 1980; Lieber, 1980; Meisuo, 2000),

b) studies on the relation between coherence, frequency of cohesive ties, and quality of written product (Allard \& Ulatowska, 1991; Johnson, 1992; Karasi, 1994; Khalil, 1989; Norment, 1994; Meisuo, 2000; Tierney \& Mosenthal, 1983),

c) comparative studies on the frequency and variety of lexical cohesive ties employed by native and non-native speakers of different languages (Connor, 1984; Field \& Yip, 1992; Guzman, Garcia \& Alcon, 2000; Johnson, 1992; Lui \& Robinet, 1990; Zanardi, 1994), and

d) research oriented towards the discovery of whether genre, or topic has any influence on the different lexical ties employed by language learners (Allard \& Ulatowska, 1991; Norment, 1994; Tierney \& Mosenthal, 1983).

In their review, Jimenez Catalan \& Moreno Espinosa reached four conclusions, one of which supports Hasan (1984) and Hoey's (1991) finding that lexical cohesion is the most frequent category among other types of cohesion. Support to Jimenez Catalan, and Moreno Espinosa's finding also comes from Allard and Ulatowska (1991), who, in their study on the relationship between the number of lexical and conjunctive ties and text quality, underline this important relationship. Despite the studies on the frequency of cohesive ties used by language learners and despite the comparative studies on the frequency and variety of lexical cohesive ties employed by native and non-native speakers of different languages, to the best of the writer's knowledge, no comparative study on the frequency and variety of lexical cohesive ties employed by Turkish learners of English in their Turkish and English stories has been carried out so far. Yet knowledge on the relationship between learners' employment of lexical reiteration in their own language and in the foreign language might prove to be a key factor. Hence, I believe that this research could be useful for English language teachers, learners, and for the domain, particularly it;

a) may provide valuable information on the employment of lexical reiteration, both quantitative and qualitative, of Turkish learners of English in Turkish and English,

b) might shed some light on the possible relationships between learners' employment of lexical reiteration in these two languages,

c) might encourage us to help learners benefit from what they already know and are able to do in their mother tongue, and

d) might spark interest and enthusiasm into how this issue could be approached from a different perspective and lead us to question our existing approach to the teaching of lexical cohesion in writing courses.

Retaining the above in mind, the main purpose of this study is to investigate EFL learners' ability in composing cohesive texts in their first language and in English as their foreign language, and to investigate whether there are any similarities between these two languages in terms of composing cohesive texts. This study mainly aims to consider: 
a) the types of lexical reiteration Turkish learners of English employ in Turkish,

b) the types of lexical reiteration Turkish learners of English employ in English, and

c) any similarities between the type(s) of lexical reiteration employed in these two languages.

\section{Methodology}

This descriptive study was conducted with the participation of 40 intermediate level students. This study employs both qualitative and quantitative approaches, comprising frequency counts and text analysis of twenty semi-guided picture stories both in Turkish and in English based on a set of pictures, depicting what happened before, during and after a fire incident which broke out at an apartment. The pictures, which displayed eight episodes, were given in chronological order. Apart from this, the data of the study also came from a synonym vocabulary test and semi-structured interviews held with randomly chosen 10 students to dig deeper into their understanding of achieving textual cohesion. Semi-structured interview was preferred as it helped the writer create a positive rapport with the interviewees, which was essential for them to freely and comfortably express their own views in their own terms on the issue discussed. This positive atmosphere also helped reach valid and reliable data, since the interviewees could express their ideas in detail, with no direction from the interviewer whatsoever.

\subsection{Data Collection Procedure}

The data were collected in two different sessions with a three-week period slot in between the slots. The same set of pictures was used in both sessions with both groups. As the data consisted of the written accounts of the picture story, the participants were asked to write a story based on the set of pictures given in one of their class hours. They were allocated 45 minutes for the task and were told that they could write the story either in a paragraph or in an essay format, and it was emphasized that they were free to add any extra detail they wished. Both groups wrote the story in both their native language and in English. While the first group carried out the task first in English, the second group did it first in Turkish. This was planned mainly to decrease any likely influence of the language used in the first session on that of the one used in the second session. In addition to this, the second session was held after a three-week period slot in order to prevent direct translations from the first version. Three weeks after the first session, the second session was held. At this point, the groups carried out the same task using the language they did not use in the first session.

\subsection{Data Analysis}

After the collection of the data from 40 students, twenty stories, ten from the first group and ten from the second group, were randomly selected and analyzed in terms of the employment of different types of lexical cohesion both qualitatively and quantitatively by the researcher himself and a senior teacher independent of each other. In case of disagreement, which was rare, discussions under the auspices of a third senior teacher were held and consensus on the disputed issues was reached.

\section{Results}

\subsection{Employment of Lexical Cohesive Devices, Reiteration, in Turkish and English}

\subsubsection{Employment of Lexical Reiteration in Turkish}

The first question I hoped to explore in this study was the types of lexical reiteration Turkish learners of English employ in Turkish. As it can be seen from figure 1, Turkish learners of English used repetition predominantly to create cohesion in their stories. Compared to repetition, they employed both superordinate and synonym or near-synonym words less, especially synonyms and/near synonyms. Another apperant similarity is that the precentages of both groups showing the amount of their use is quite close.

\subsubsection{Employment of Lexical Reiteration in English}

As it is the case with their employment of lexical reiteration in Turkish, the participants heavily used repetition to have cohesion in their English stories. Figure 2 shows that they used repetition far more than the other two types of reiteration. Also, the percentages of the employment of these three types of lexical cohesion in English by both groups are strikingly very close. This finding might give us some significant information about the relationship between their employment of lexical cohesion in Turkish and English, which will be discussed in the next section.

\subsubsection{Employment of Lexical Reiteration in Turkish and English}

Another question I aimed to explore in this study was whether there were any similarities between the types of lexical cohesion reiteration Turkish learners of English employ in their Turkish and English stories. The results, as apparent from Figure 3, show similar patterns between English and Turkish in terms of the employment of lexical reiteration. 
At the outset, it ought to be underlined that both groups displayed similar features in terms of the types and amount of lexical reiteration. One of these important similarities is that there seems to be a one-to-one similarity between the two languages in terms of the types of the lexical reiteration used. The participants employed repetition of the same word or phrase in both languages extensively more than the other two forms of reiteration forms. They used synonyms or near synonyms in both languages the least. This finding might reveal that their competency in employing these features in both languages is pretty similar. That is to say that, they are inclined to use the same linguistic devices with similar percentages in their own language, too. When it comes to inter-language comparison of the employment of these linguistic devices, it could be seen from Figure 3 that they significantly used repetition a little more in English. However, they used superordinate and synonym or near-synonym words a little more in Turkish. These two findings are quite understandable considering that Turkish is their mother tongue. In short, the participants used the same lexical cohesive devices in the same rank order in both languages with similar percentages. This striking uniformity between the two languages manifests itself in the repetition of the same word(s) in the stories written in both languages, which will be dealt with in the following section.

\subsection{Quantitative and Qualitative Use of Repetition, Superordinate and Synonym or Near-synonym Words in Turkish and English}

In addition to the similarity in the percentage of the employment of lexical reiteration between Turkish and English, there lies an important parallelism in the use of repetition both qualitatively and quantitatively.

\subsubsection{Quantitative and Qualitative Use of Repetition in Turkish and English}

Two important patterns related to the participants' employment of repetition deserve special attention. The first of these is that both groups repeated almost the same words in their stories in Turkish and English. While 9 of the 10 most frequently repeated words are the same in both languages in Group A's stories, 7 of the 10 most frequently repeated words are the same in both language in Group B's stories. What is more, as could be seen from Tables 1 and 2, even the first two of the top three most frequently repeated words are the same in both groups' stories in both languages.

Apart from this intra-group pattern, a striking inter-group similarity is worth mentioning. While 6 of the 10 most frequently repeated items of both groups are the same in English, this number is 4 in Turkish. This feature could be interpreted to the effect that the participants in both groups kept repeating the same words in English, which might hint their relatively low competency in creating cohesion in English by using lexical reiteration. However, it must be underlined that the synonyms or near-synonyms of the most frequently repeated words such as 'fire, woman, house, servant, scream, rescue, paper, and maid' are among the most frequent 3000 English words which the participants (intermediate learners of English) are supposed to know and use productively according to the objectives of the school.

At places, the repetition of the same word occurs so densely and consecutively that it gives the text a monotonous or unpleasant tone as seen in example 1.

\section{Example 1}

...As soon as the firemen saw the building in flames, they hurried to it, but the firemen couldn't approach the building because of the flames. Then the firemen asked people if the building had another entrance...

As seen in this example, the student used the words 'firemen' and 'building' three times each in just two lines while he could have used some synonym or near synonym words to denote the same concept. A similar pattern was also observed in the repetition of the same words in Turkish, though not so densely as seen in example 2 .

\section{Example 2}

...Hizmetçi mutfakta cay yaymakla meşguldü. Dışarıdan gelen bağrışmaları duyar duymaz çayı bırakıp mutfaktan salona geçti. Salondaki pencereden dışarı bakarken birden mutfaktan kokular geldiğini fark etti...

(...The servant was making tea in the kitchen. As soon as she hear the loud noise coming from outside, she quit making tea, left the kitchen and went into the living room. While looking outside through the window in the living room, she recognized smell coming from the kitchen...)

As underlined above, the participants relied heavily on repetition, especially in their English stories, as summarized in Table 3. As is apparent from table 3, they repeated more words in English and repeated them more when compared to Turkish. Also, the number of repeated words in both languages is quite close, so is the percentage of their repetition.

\subsection{Superordinate Word Use in Turkish and English}

Super-ordinate word use to create cohesion in both languages also shows some similar patterns, two of which draw 
attention. The first of these is that both groups used slightly more superordinate words in Turkish as shown in table 4.

The latter point is that they denoted to the same concepts in both languages as in examples 3 and 4 .

Example 3

...As soon as the people outside saw the building in flames, they screamed to inform the people inside the building. Then they saw that their effort paid for as a woman appeared at a window. They pointed to the maid that...

In example 3, the participant used the word 'people' as a superordinate word and then used the word 'woman' to refer to the same entity. Also, the same participant used 'woman' as superordinate word and 'maid' to refer to it. The same pattern of usage could also be found in Turkish as given in example 4 .

Example 4

...Yangını gören insanlar sokakta toplanmaya başladılar. Bazı vatandaşlar olup biteni anlamaya çalışırken, erkeklerden bazıları itfaiyeye telefon etmeye çalışıyor, bazı erkekler de etraftan yardım bulmaya çalışıyorlardı...

(The people who saw the fire began to group in the street. While some citizens were trying to understand what was happening, some men were trying to call the fire-brigade, some men were trying to get help...)

\subsection{Synonym or Near-synonym Word Use in Turkish and English}

As shown in figure 3, the participants employed synonym or near-synonym words the least to create cohesion in their stories in both languages, though they used slightly more synonym words in Turkish. The finding that they were able to use the synonym or near synonyms of just a few Turkish words was unexpected, since Turkish is their mother tongue. It goes without saying that they do know the synonyms of all of the words they used as repetition over and over again. Another surprising observation was that they were able to use just four synonym words in English as shown in table 5. They were expected to have done better as they had a relatively high level of English proficiency.

In order to be able to have an idea whether this problem was related to receptive or productive skills, the participants were given a synonym and/or near-synonym word test and asked to provide the most frequently repeated words and define them. As is normally expected of learners of this particular English proficiency level, they could provide synonym or near synonyms to nine words out of eleven, with varying percentages as given in figure 4 .

To dig deeper into this anticipated observation, a semi-structured interview was held with the randomly chosen 10 participants, who were asked to comment on why they did not use the synonyms of the words which they knew. As the semi-structured interviews created a positive rapport with the participants, they expressed their own views in their own terms on the issue discussed freely and comfortably. Although they expressed their ideas in detail and depth, with no direction from the interviewer, more than half of them could probe the notion 'cohesion', which strengthened the reliability and validity of the data. The interviews highlighted two important revelations: a) they had no idea of cohesion and its importance in creating text; b) they did not know that using synonyms or near-synonyms contribute to lexical cohesion, either in Turkish or in English.

\section{Discussion and Conclusion}

It is important to point out that the purpose of this exploratory study was to analyze how learners of English create lexical cohesion both in Turkish and English and to formulate some possible interpretations of the results. It is of course virtually impossible to make broad generalizations because of the relatively limited quantity of the data. It is a fact that much more research is needed to understand intricate relationships between creating cohesion in L1 and L2 via lexical reiteration device use. Indeed, locating and fully understanding this rather complicated matter is difficult largely because of the existence of numerous factors affecting the issue. Although this study offers no definite clear-cut one-to-one explanation for the participants' relatively low ability in composing cohesive texts in both languages by using lexical reiteration devices, some of the findings could hopefully give insight into the issue. The forthcoming knowledge could encourage English teachers to look at the issue from a different perspective.

In this article, some of the devices for constructing cohesion in Turkish and English, and the similarities between the cohesive devices employed in these two languages have been studied. The findings have shown that the participants relied mainly on repetition in both languages, followed by superordinate words, and synonym or near-synonym word use consecutively in both languages. While almost $70 \%$ of the lexical reiteration devices used in English stories consist of repetition, over $55 \%$ of the lexical reiteration devices used in Turkish stories is projected the same stance. These results are similar to those found by Connor (1984) in her analysis of cohesion in the writings of ESL students. She found that ESL students had high percentages of lexical reiteration (Ll), 84\%, with relatively smaller numbers of synonymy and collocation. Similarly, in his study on cohesion and coherence in Arab EFL college 
students' writing, Khalil (1989) found that Arab students overused lexical cohesive ties, especially reiteration of the same word. Also, Mojica's study on reiterations in ESL learners' academic papers showed that repetition was the most frequently used type of lexical cohesion (2006). At this stage, it is worth mentioning once more that almost all of the lexical reiteration ties are repetitions of the same lexical items. This overreliance on repetition and rather relative underuse of superordinate and synonym or near-synonym words in both languages suggest the participants' parallel competency in both languages. Although the participants' low proficiency in employing lexical cohesive devices in constructing text in English is understandable to some extent, their low proficiency in employing lexical cohesive devices in constructing text in Turkish is rather surprising, since Turkish is their native language. This unexpected finding, coupled with the observation that they tended to avoid using synonyms or near-synonyms of the $90 \%$ of the repeated words, seems to lead to two conclusions: they are either unaware that they can create cohesion by using lexical reiteration devices or they cannot put it into practice even in their native language. This conclusion was supported by the information gathered via the semi-structured interviews. The semi-structured interviews held with the ten randomly chosen participants have indicated that they neither knew this concept nor could they create cohesion by using lexical cohesive devices even in Turkish, let alone in English. The interviews have also unearthed an important reason lying behind their excessive preference for repeating the same word: that it is a common discourse strategy they had acquired during their secondary and high school years and have used unconsciously since, especially when they come up with no other word to state the same concept. Another possible cause of the problem could be that although textbooks and grammar books abound in examples of cohesion of other types, lexical cohesion is rarely dealt with, ignoring this seemingly minor but important issue. As such, teachers as well as language learners seem to be left alone to solve the problem on their own. This surprising finding might lead to the suggestion that if learners are given consciousness raising training on how to achieve lexical cohesion in their Turkish texts, this might help them transfer this into English or vice versa.

Though writing is dependent on knowledge of grammar and vocabulary to a great extent, it is more than the sum of grammar and vocabulary knowledge. Given that a great number of learners having somewhat adequate knowledge of vocabulary and grammar but being inefficient in writing skillfully, coherently and cohesively, we can say that something crucial is missing. Though students have the knowledge necessary for writing especially in their mother tongue and in English to a certain extent, they seem to have difficulty in making full use of this in their writing endeavors. The reason for this could be the language instruction they previously had, both Turkish and English as a foreign language. This could be partially supported with the observation that though writing teachers generally talk about learners' incoherent and incohesive pieces of writings, these and the other linguistic mechanisms that make a text coherent and cohesive are rarely but vaguely dealt with as is underlined by Lee (2002). By drawing attention to the same problem and underlying the claim that something is wrong with how cohesion is viewed, Witte \& Faigley (1981) underscore that cohesion can be better taught if it is better understood. They also stress the fact that not adequate training is given in most college writing classes. Given this lack of adequate training on this issue and its benefits, we do have some studies with promising results. On his study on cohesive devices in students' writing tasks, Majdeddin (2010) found that overt instruction is a predictor of success in the use of cohesive ties in writing tasks, highlighting especially the finding that the greatest improvement was observed in the use of reference and superordinate words.

Given the observations obtained from this small scale study, a number of suggestions could be made to help solve the problem. Moving from the finding of this study that the learners were poor in employing lexical cohesion not only in English but also in their own mother tongue could be made use of in the process of consciousness training on lexical cohesion. Drawing on the findings of this study, cohesion and its importance, and how it is achieved in Turkish could be emphasized and a consciousness-raising training could be given to learners on cohesion, especially lexical cohesion, and how it is realized it in English.

\section{References}

Allard, L., \& Ulatowska, H. K. (1991). Cohesion in written narrative and procedural discourse of fifth-grade children. Linguistics and Education, vol. 33(1), 63-79. http://dx.doi.org/10.1016/0898-5898(91)90024-D

Connor, U. (1984). A study of cohesion and coherence in English as a second language students' writing. Papers in Linguistics: International Journal of Human Communication, 17, 301-316

De Breaugrande, \& Dressler. (1981). Introduction to text linguistics. London: Longman.

Emeksiz, Z. E. (1998). Local Coherence Problems in Written Narratives of Adult EFL Learners: Topical NP Usage in Various Discourse Contexts. (MA Thesis). Eskişehir, Anadolu University.

Friedlander, A. (1990). Composing in English: effect of a first language on writing in English as a second language. In Barbara Kroll (Editor), Second Language Writing. CUP. 
Givon, T. (1983). Topic Continuity in Discourse. Amsterdam, John Benjamins Publishing Company.

Goutsos, D. (1997). Modeling Discourse Topic: Sequential Relations and Strategies in Expository. Text, vol. LIX. In the series Advances in Discourse Processes. New Jersey, Ablex Publishing Corporation.

Grabe, W., \& Kaplan, R. (1996). Writing a second language: Contrastive rhetoric. In D. Johnson, \& D. Roen (Eds.), Richness in Writing: Empowering ESL students, 263-283. New York: Longman.

Guiju, Z. (2005). The cohesive knowledge and English writing quality of college student. CELEA Journal, vol. 28(3), 24-30

Halliday, M. A. K., \& R., Hasan. (1976). Cohesion in English. UK, Longman Group Ltd.

Hoey. (1991). Patterns of lexis in text. Oxford: Oxford University Press.

Jimenez Catalan., R., \& Mereno Espinosa, S. (2005). Lexical cohesion in English L2 students' composition. In Salazar, P., Esteve, M. J.; \& Codina, V. (eds.), In Teaching and learning the English language from a discourse perspective. Castello: Universitat Jaume I.

Jones, S., \& Tetroe, J. (1987). Composing in a second language. In A. Matsuhashi (Ed.), Writing in real time (pp. 34-57). Norwood, NJ: Ablex.

Khadijeh Majdeddin (2010) Cohesive devices in students' IELTS writing tasks. International Journal of Language Studies (IJLS), vol. 4(2), 1-8

Khalil, A. (1989) A study of cohesion and coherence in Arab EFL college students' writing. System, vol. 17(3), 359-371. http://dx.doi.org/10.1016/0346-251X(89)90008-0

Koyabashi, H., \& C. Rinnert (2002). High school student perceptions of first language literacy instruction: implications for second language writing. Journal of Second Language Writing, vol. 11(2), 91-116. http://dx.doi.org/10.1016/S1060-3743(02)00067-X.

Mojica, L., A. (2006). Reiterations in ESL learners' academic papers: Do they contribute to lexical cohesiveness? The Asia-Pacific Education Research December, 15(1), 105-125

Lay, N. (1982). Composing process of adult ESL learners: A case study. TESOL Quarterly, 16, 406-411

Lee, I. (2002). Teaching Coherence to ESL students: a classroom inquiry. Journal of Second language Writing, vol. 11(2), 135-159. http://dx.doi.org/10.1016/S1060-3743(02)00065-6.

Leki, I. (2002). Second Language Writing. In Robert B. Kaplan (Editor), The Oxford Handbook of Applied Linguistics. Oxford University Press.

Nunan, D. (1999). Second Language Teaching \& Learning. Boston, Heinle \& Heinle Publishers.

Richards, J. C., J. Platt, \& H. Platt (1992). Dictionary of Language Teaching \& Applied Linguistics. UK, Longman Group Limited.

Subaşı, L. U. (2000). Metin Üretimi. In Türkçe Sözlü ve Yazılı Anlatım. Canan İleri (Ed.). Eskişehir, Anadolu Üniversitesi.

Wang, W., \& Wen, Q. (2002). L1 use in the L2 composing process: An exploratory study of 16 Chinese EFL writers. Journal of Second Language Writing, vol. 11(3), 225-246

Witte, S. P., \& Faigey L. (1981). Coherence, cohesion, and writing quality. College and Composition, vol. 32(2), Language studies and composing, 189-204. http://dx.doi.org/10.1016/S1060-3743(02)00084-X 
Table 1. The 10 most frequently repeated lexical items in rank order (Group A)

\begin{tabular}{|c|c|c|c|c|c|}
\hline \multicolumn{4}{|c|}{ English } & \multicolumn{2}{|c|}{ Turkish } \\
\hline & repeated item & \# of repetition & & repeated item & \# of repetition \\
\hline 1 & fireman & 36 & 1 & hizmetçi (servant) & 52 \\
\hline 2 & servant & 24 & 2 & itfaiye (fire brigade) & 36 \\
\hline 3 & fire & 24 & 3 & balkon (balcony) & 24 \\
\hline 4 & tea & 16 & 4 & yangın (fire) & 16 \\
\hline 5 & kitchen & 16 & 5 & çay (tea) & 16 \\
\hline 6 & bomb & 12 & 6 & bomba (bomb) & 12 \\
\hline 7 & housemaid & 12 & 7 & mutfak (kitchen) & 8 \\
\hline 8 & maid & 12 & 8 & kurtarmak (rescue) & 8 \\
\hline 9 & rescue & 12 & 9 & duymak (hear) & 8 \\
\hline 10 & old man & 12 & 10 & otel (hotel) & 8 \\
\hline
\end{tabular}

Table 2. The 10 most frequently repeated lexical items in rank order (Group B)

\begin{tabular}{|cccccc|}
\hline & \multicolumn{2}{c}{ English } & & & \multicolumn{2}{c|}{ Turkish } \\
1 & repeated item & \# of repetition & & repeated item & \# of repetition \\
2 & fire & 92 & 1 & itfaiye (fire brigade) & 28 \\
3 & fireman & 44 & 2 & ev (house) & 20 \\
4 & woman & 32 & 3 & duman (smog) & 16 \\
5 & house & 24 & 4 & çı̆glik (scream) & 16 \\
6 & tea & 24 & 5 & kurtarmak (rescue) & 12 \\
7 & servant & 16 & 6 & misafir (guest) & 12 \\
8 & scream & 16 & 7 & firın (bakery) & 8 \\
9 & rescue & 12 & 8 & patlama (explosion) & 8 \\
10 & police & 12 & 9 & çay (tea) & 8 \\
\hline
\end{tabular}

Table 3. Number and percentages of the repeated words in English and Turkish

\begin{tabular}{|lccc|}
\hline & & \# of the repeated words & \# of repetition \\
Group A & English & 20 & 264 \\
& Turkish & 15 & 232 \\
Group B & English & 18 & 348 \\
& Turkish & 14 & 224 \\
\hline
\end{tabular}


Table 4. Super-ordinate word use

\begin{tabular}{|c|c|c|c|c|c|}
\hline & \multicolumn{2}{|c|}{ Group A } & \multicolumn{3}{|c|}{ Group B } \\
\hline & English & Turkish & & English & Turkish \\
\hline 1 & people & insanlar & 1 & people & olay \\
\hline 2 & woman & vatandaşlar & 2 & woman & yangin \\
\hline 3 & maid & erkekler & 3 & servant & insanlar \\
\hline 4 & & itfaiye ekibi & 4 & & vatandaşlar \\
\hline 5 & & itfaiye elemanı & 5 & & erkekler \\
\hline 6 & & olay & 6 & & itfaiye elemanı \\
\hline 7 & & yangın & & & \\
\hline
\end{tabular}

Table 5. Synonym or near-synonym word use in Turkish and English

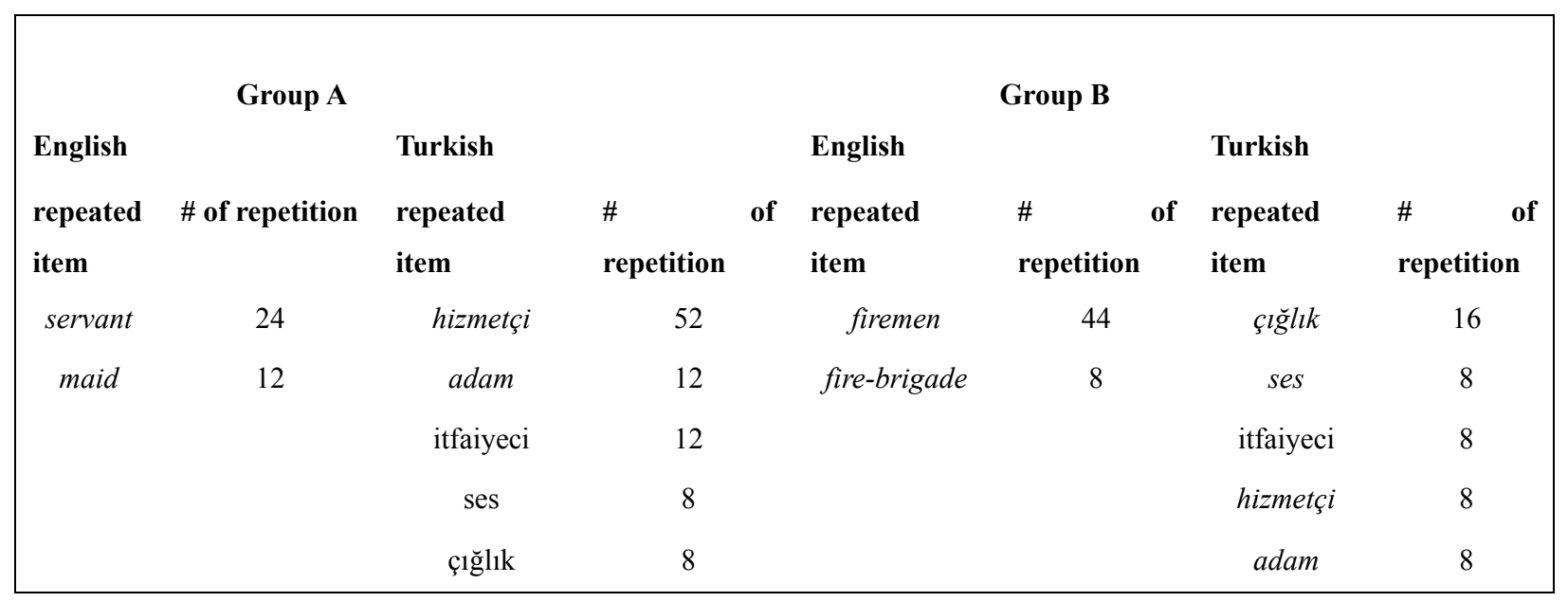

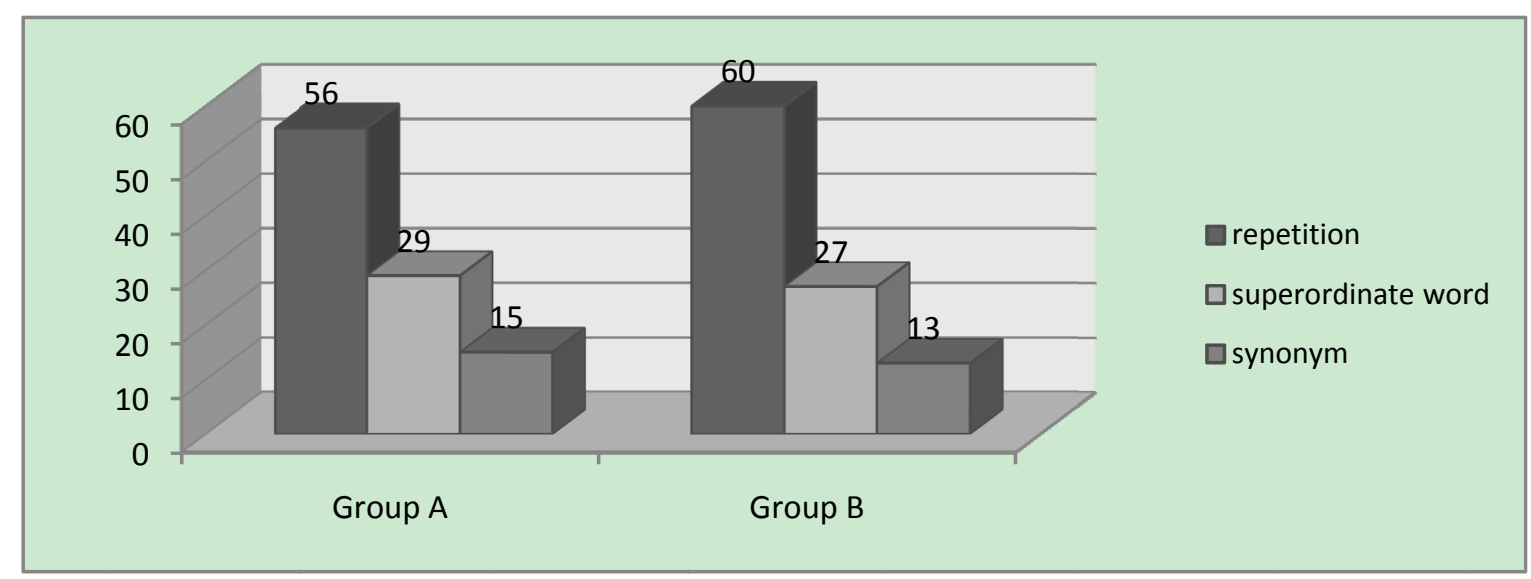

Figure 1. The percentages of the reiteration employed in Turkish 


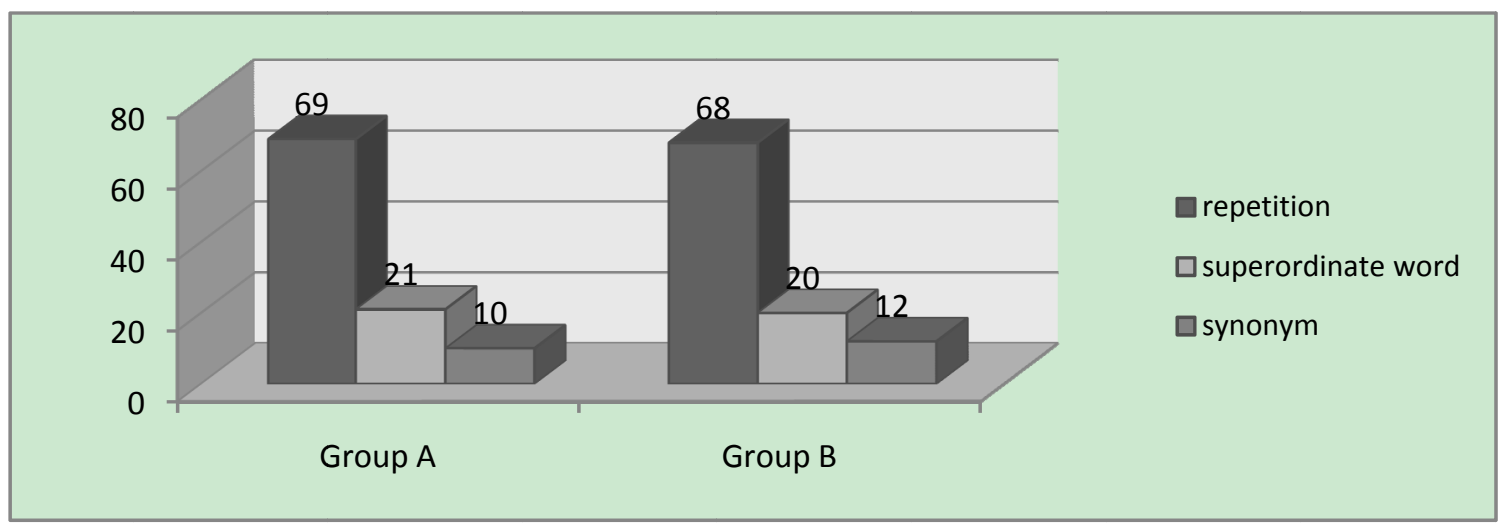

Figure 2. The percentages of the lexical reiteration employed in English

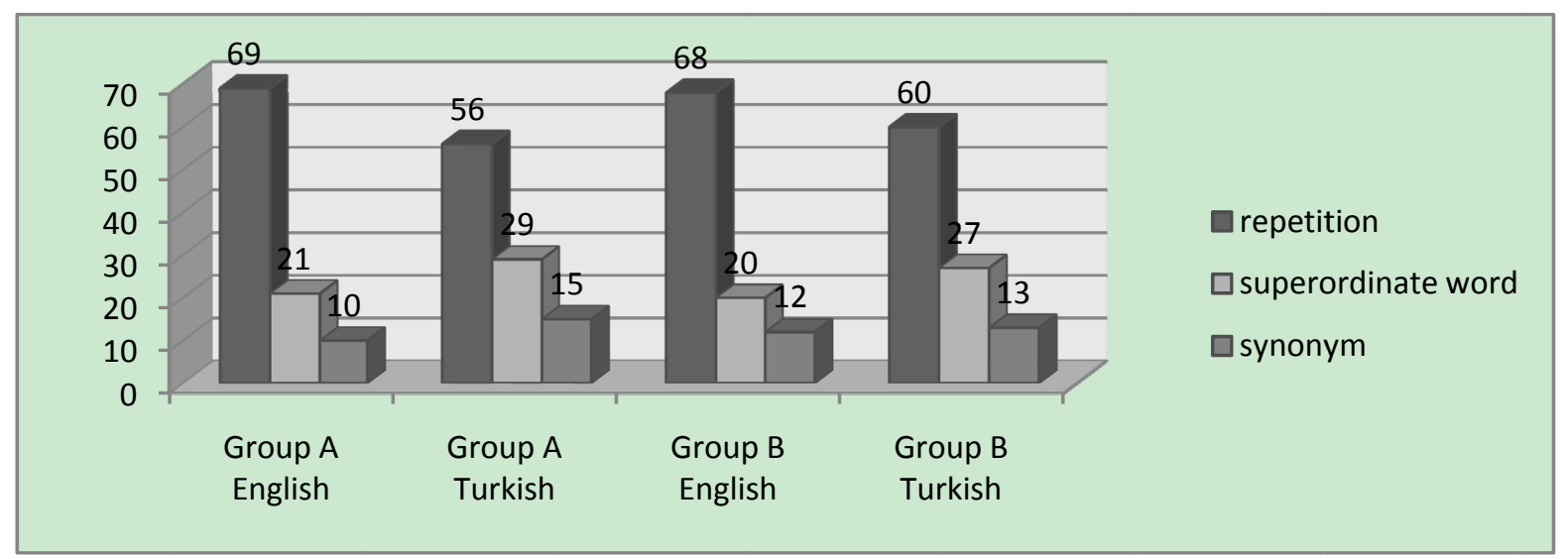

Figure 3. The percentages of the lexical reiteration employed in Turkish and English

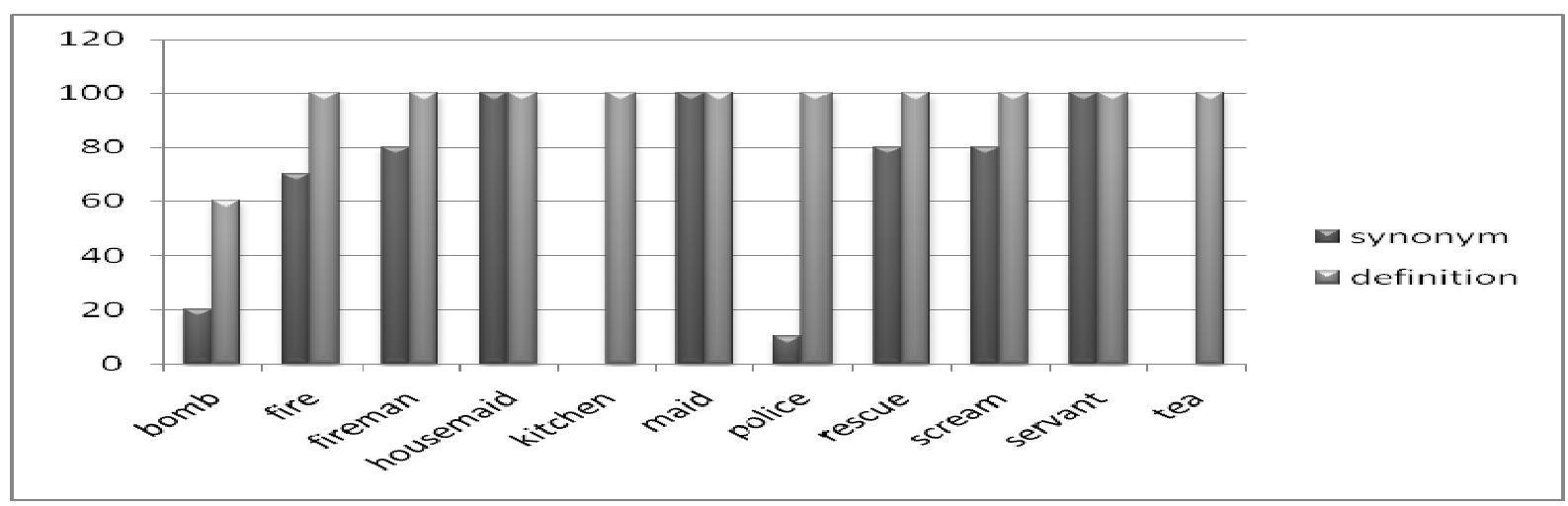

Figure 4 . The percentage of synonym word test 